\title{
Infusion of pramlintide, a human amylin analogue, delays gastric emptying in men with IDDM
}

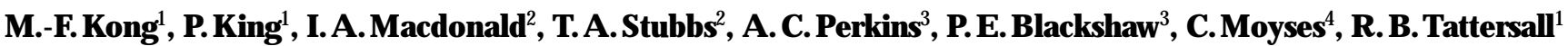 \\ ${ }^{1} \mathrm{D}$ epartment of D iabetes, U niversity H ospital Nottingham, N ottingham, UK \\ ${ }^{2}$ D epartment of Physiology and Pharmacology, U niversity of N ottingham M edical School, N ottingham, U K \\ ${ }^{3}$ D epartment of M edical Physics, U niversity H ospital Nottingham and U niversity of N ottingham M edical School, N ottingham, \\ UK \\ ${ }^{4}$ A mylin Pharmaceuticals, A mylin E urope Ltd, Oxford, U K
}

Summary Pramlintide, a human amylin analogue, reduces hyperglycaemia after meals in patients with insulin-dependent diabetes mellitus (IDDM). We investigated whether this was due to delayed gastric emptying. Eight men with uncomplicated IDDM were studied twice in a randomised, double-blind crossover design. E uglycaemia was maintained overnight by intravenous infusion of glucose and/or insulin and the following morning a 5-h infusion of pramlintide $25 \mu \mathrm{g} / \mathrm{h}$ or placebo was started at 08.00 hours. A t 08.30 hours the patients injected their normal morning insulin dose subcutaneously and 30 min later ate a meal ( $600 \mathrm{kcal}, 50 \%$ carbohydrate) of which the solid component was labelled with Technetium$99 \mathrm{~m}$ and the liquid with Indium-111 to quantify gastric emptying. G amma-scintigraphic images were obtained every $20 \mathrm{~min}$ for the next $4 \mathrm{~h}$. Insulin and glucose were infused as necessary to maintain blood glucose levels within $3 \mathrm{mmol} / \mathrm{l}$ of the pre-meal value. Compared to placebo, pramlintide significantly delayed emptying of both liquid (median lag time 69 vs $7.5 \mathrm{~min}$ ) and solid (median lag time 150 vs $44.5 \mathrm{~min}$ ) components of the meal. Pramlintide delayed gastric emptying so much that $t_{50}$ values could not be calculated for solid or liquid. A mylin agonists such as pramlintide may, therefore, be of value in improving glycaemic control in ID D M by modifying gastric emptying. [D iabetologia (1997) 40: 82-88]

Keywords Insulin-dependent diabetes mellitus, gastric emptying, postprandial hyperglycaemia, amylin, pramlintide.
A mylin is a 37-amino acid polypeptide co-secreted with insulin by pancreatic beta cells, in response to nutrient stimuli. It circulates at concentrations of 5$30 \mathrm{pmol} / \mathrm{l}$ in normal subjects. The peptide pramlintide is a stable tri-substituted non-aggregating analogue of amylin [1] which in animal studies has biological activities similar to endogenous amylin. D oses of pramlintide resulting in plasma concentrations equivalent to physiological plasma amylin levels can attenuate

Received: 22 March 1996 and in revised form: 24 September 1996

Corresponding author: D r. M .-F.K ong, D iabetes U nit, U niversity Hospital, Queen's Medical Centre, Nottingham, NG 7 2U H, UK

A bbreviations: ID D M , I nsulin-dependent diabetes mellitus; 3OM G, 3-ortho-methylglucose; SM A, superior mesenteric artery; $\mathrm{A} \cup \mathrm{C}$, area under the curve; ROIs, regions of interest; $\mathrm{CV}$, coefficient of variation; TA V , time-averaged mean velocity. the postprandial glucose excursion in patients with insulin-dependent diabetes mellitus (ID D M ) [2]. Possible mechanisms are delay in gastric emptying, reduction in glucose transport across the intestinal wall, intestinal vasoconstriction, or a combination of these or other factors. In animal studies amylin reduces the plasma glucose rise following an oral glucose load by slowing gastric emptying $[3,4]$.

The objective of this study was to determine the effect of pramlintide on the rate of gastric emptying, superior mesenteric artery (SM A) blood flow, and 3-ortho-methylglucose (OMG) absorption in IDDM patients.

\section{Subjects and methods}

Subjects. E ight healthy non-obese males (B M I $23.6 \pm 2.6 \mathrm{~kg} / \mathrm{m}^{2}$, mean \pm SD) with uncomplicated IDDM , aged $32.5 \pm 10$ years (mean $\pm S D$, range 22-46) were recruited. M ean duration of 
diabetes was $11 \pm 6.1$ years (mean $\pm \mathrm{SD}$ ) and $\mathrm{HbA}_{1 c}$ was $8.6 \pm 1 \%$ (mean $\pm S D$, normal up to $6.1 \%$ for the assay, SciCor L aboratories, G eneva, Switzerland). A II had a basal C-peptide level $<1.0 \mathrm{ng} / \mathrm{ml}$ (analysed at Laboratoire R iotton, G eneva, Switzerland), and were taking no medication apart from insulin. None had autonomic neuropathy, as assessed clinically and by tests of cardiovascular reflexes, including the heart rate response to the Valsalva manoeuvre, during deep breathing, and to standing (30:15 ratio). Informed consent was obtained from all subjects. The study was approved by the B ritish D epartment of $\mathrm{H}$ ealth ( $\mathrm{A}$ dministration of $\mathrm{R}$ adioactive Substances A dvisory Committee) and the research ethics committee of the U niversity H ospital, Q ueen's M edical Centre, $\mathrm{N}$ ottingham.

Protocol. E ach subject underwent two gastric emptying studies in a randomized, double-blind, placebo-controlled crossover design. On one occasion they received pramlintide $(25 \mu \mathrm{g} / \mathrm{h})$ and on the other occasion placebo. The current dose of pramlintide was selected since it had already been shown to be active in blunting postprandial hyperglycaemia [5]. E ach subject was admitted on the evening before the study day and euglycaemia (blood glucose 5-8 mmol/l) was maintained overnight by intravenous infusion of insulin and/or glucose. A cannula was inserted into an antecubital vein for hourly blood glucose sampling and subsequently used for infusion of study drug. The next morning another cannula was inserted retrogradely, under local anaesthetic, into a vein on the dorsum of the dominant hand; it was kept patent with a slow infusion of $0.9 \%$ $\mathrm{NaCl}$ solution and the hand rested in a hot box $\left(55-60^{\circ} \mathrm{C}\right)$ to obtain "arterialized" venous blood samples. Pharmacokinetic samples were also drawn from this cannula.

Fifteen minutes before and immediately before the study drug infusion, arterialized blood samples were taken for estimation of blood and plasma glucose levels, plasma levels of 3$O M G$, and insulin. A t approximately 08.00 hours ( $t=0 \mathrm{~min}$ ) the infusion was started. A t 08.30 hours the subject injected his usual morning dose of insulin subcutaneously (24 \pm $17.6 \mathrm{IU}$, mean \pm SD ) and, at 09.00 hours, within $10 \mathrm{~min}$, ate a test meal consisting of turkey, potatoes, vegetables (including mushrooms) and low-fat milkshake which provided $50 \%$ carbohydrate (of which $70 \%$ was starch), $35 \%$ fat, $15 \%$ protein with a total of $600 \mathrm{kcal}$. The mushrooms were labelled with $3 \mathrm{MBq}$ non-absorbable ${ }^{99 \mathrm{mT}} \mathrm{c}$ tin colloid, and the milkshake with $0.5 \mathrm{MBq}$ non-absorbable ${ }^{111} \mathrm{I}$-D TPA -diethylenetriaminepentaacetic acid (DTPA) [6]. The milkshake also contained 3-OM G so that its appearance in the peripheral circulation could be used as an index of glucose absorption. $G$ astric emptying data were acquired with 30-s anterior and posterior images of the stomach [7] every 20 min during the 5-h infusion using an IGE maxi-camera gamma camera (D epartment of M edical Physics, U niversity of Nottingham M edical School, Nottingham, UK ) fitted with a low-energy general purpose collimator. The gamma camera was linked to a dedicated N uclear Diagnostics nuclear medicine computer system. R egions of interest (R OIS) were created around the computer-generated image of the stomach for both anterior and posterior images, and counts were recorded. The geometric mean of the anterior and posterior measurements was calculated and counts were corrected for background radiation, isotope decay and cross-talk between the energy windows. For each of the three R O Is (proximal, distal, and total stomach), activity time curves, expressed as a percentage of total meal against time, were derived. Various emptying parameters were calculated from these curves. The coefficient of variation (CV) for $t_{50}$ in normal subjects was $5 \%$.

SM A blood flow was determined every 30 min using transcutaneous D oppler ultrasound [8] with a $3.5 \mathrm{M} \mathrm{H} z$ imaging system and a $3 \mathrm{MHz}$ D oppler frequency. The angle of insonation was recorded and used to convert the Doppler shift values $(\mathrm{kHz})$ into blood flow velocity $(\mathrm{cm} / \mathrm{s})$. R ecordings were made with the subject's breath held at full inspiration and stored on videotape. Mean values of time-averaged mean velocity (TA V , calculated using the intensity weighted mean frequency) and peak systolic velocity were taken from at least $10 \mathrm{D}$ oppler wave form complexes. The TA V s were used in the calculation of absolute flow $(\mathrm{ml} / \mathrm{min})$. Manually operated calipers were used to estimate vessel diameter to give readings with an accuracy of $1 \mathrm{~mm}$. The diameter was taken as the mean of four measurements from the proximal portion of the vessel. It was assumed that the vessel diameter remained unchanged during the infusion period. Blood flow was calculated according to the formula: $3.142 \times \mathrm{D}^{2} \times \mathrm{TAV} \times 60 / 4 \mathrm{ml} / \mathrm{min}$ where $\mathrm{D}=$ vessel diameter, $\mathrm{TA} \mathrm{V}=$ Time averaged velocity. The CV between days in fasting subjects was $5-6 \%$.

A rterialised blood samples, for measurement of 3-OM G and free insulin were taken every $15 \mathrm{~min}$ for the first hour after the meal and then every 30 min for the rest of the infusion period. B lood glucose levels were measured every $10 \mathrm{~min}$ after the meal using a Y ellow Springs A nalyser (Y ellow Springs, O hio, U SA ); CV for the assay was $3 \%$. Plasma was stored in fluoride oxalate for subsequent determination of 3-O M G by gas-liquid chromatography $[9,10]$ (intra-assay CV $1.8-5.7 \%$ ). Serum insulin concentrations were analysed at SciC or, I nc., Indianapolis, Ind., U SA (intra-assay CV 2.7-4.6\%, inter-assay CV 6.3$9.7 \%$ ). A rterialized blood samples were taken at $30 \mathrm{~min}, 1 \mathrm{~h}$, $3 \mathrm{~h}$ and $5 \mathrm{~h}$ for pramlintide levels which were assayed using a validated immunoradiometric assay method at A mylin Pharmaceuticals I nc., San Diego, Calif., U SA (intra-assay CV 3.4$5.5 \%$, inter-assay CV $5.2-5.5 \%$ ).

A fter the meal, for the rest of the infusion period, insulin and/or glucose was infused to maintain blood glucose within the normal postprandial range, to prevent a possible confounding effect of hyperglycaemia on gastric emptying. Thus, blood glucose concentration was prevented from falling below the pre-meal value or from rising to more than $3 \mathrm{mmol} / \mathrm{l}$ above the pre-meal value.

Patients returned to the clinic after 7-14 days for the alternative study drug infusion.

\section{Statistical analysis}

Conventional methods were used to calculate means, medians, SE M and SD. A ll statistical tests were two-tailed. D ue to the number of values that were not observable for the gastric emptying parameters, it wasfelt that non-parametric analyses, based on ranks, were more appropriate than two-period crossover analyses. Since non-parametric tests were employed, descriptive statistics for gastric emptying were presented as medians. If more than $75 \%$ of the values were represented as "greater than" at a particular time point, then the median was not determined. The lag time, defined as the delay between the ingestion of food and definite start of emptying (this is taken as the time taken for at least $10 \%$ of isotope to empty) and $t_{50}$, defined as the time at which $50 \%$ of the isotope has left the stomach, were analysed by Wilcoxon Signed R ank Test. A II other data were analysed by two-period crossover analysis of variance. A $p$ value less than 0.05 was considered significant in all analyses.

\section{Results}

A 5-h intravenous infusion with either pramlintide or placebo was begun at $0 \mathrm{~min}$. Patients injected their 


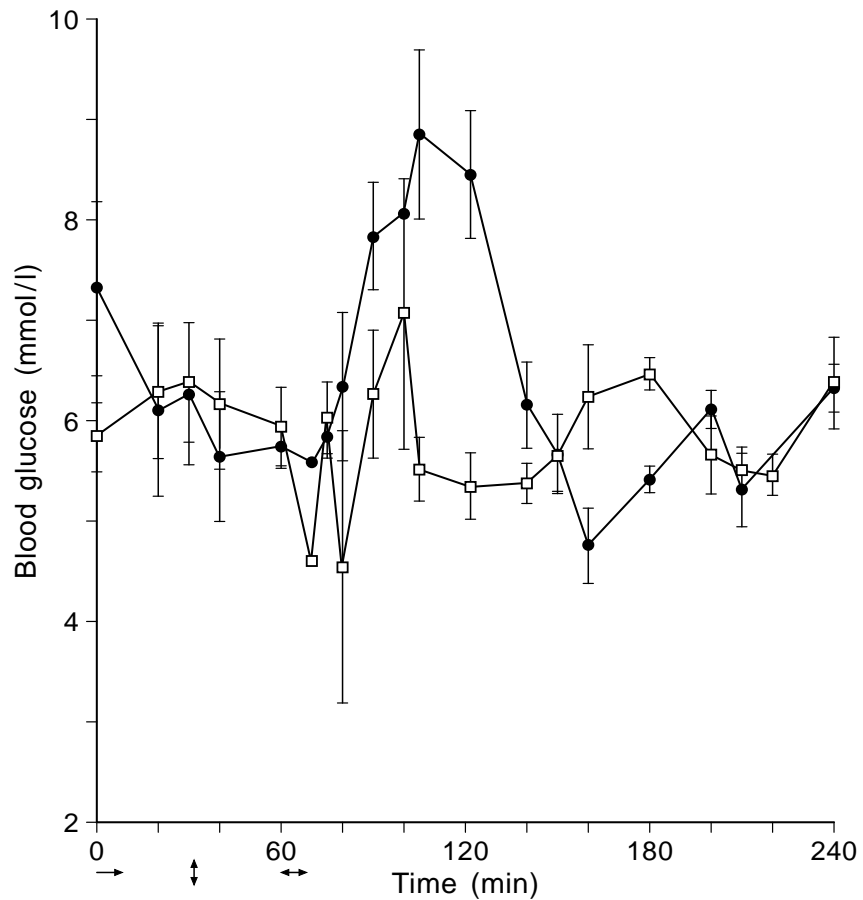

Fig. 1. Blood glucose levels during pramlintide $(\square)$ and placebo ( $)$ infusions. $\rightarrow$ start of 5 -h i.v. infusion, $\uparrow$ time of insulin injection and $\leftrightarrow$ time of meal. Data are mean \pm SE M. Peak blood glucose was significantly lower during pramlintide than during placebo infusion

insulin at 30 min and ate a standardized test meal at $60 \mathrm{~min}$.

Plasma level of pramlintide. The mean plasma pramlintide concentrations during the 5 -h intravenous infusion were $6 \pm 5 \mathrm{pmol} / \mathrm{l}$ at $30 \mathrm{~min}, 14 \pm 6 \mathrm{pmol} / \mathrm{l}$ at $1 \mathrm{~h}, 121 \pm 17 \mathrm{pmol} / \mathrm{l}$ at $3 \mathrm{~h}$ and $108 \pm 20 \mathrm{pmol} / \mathrm{l}$ at $5 \mathrm{~h}$.

Blood glucose level (Fig.1). Blood glucose level at 0 min was not significantly different between study days $(7.3 \pm 0.9$ for placebo vs $5.8 \pm 0.3 \mathrm{mmol} / \mathrm{l}$ for pramlintide). Peak blood glucose level was significantly lower during pramlintide $(7.9 \pm 0.5 \mathrm{mmol} / \mathrm{l})$ than during placebo infusion $(10.4 \pm 0.5 \mathrm{mmol} / \mathrm{l})$, $p=0.023$. There were no significant differences between pramlintide and placebo in the overall patterns of blood glucose response (no significant difference in area under the curve ( $A \cup C)$ ).

Serum insulin level (Fig.2). Serum insulin level at $0 \mathrm{~min}(56.0 \pm 19.0$ for placebo vs $42.7 \pm 13.8 \mathrm{pmol} / \mathrm{l}$ for pramlintide) were not significantly different. H owever, the peak serum insulin level and the peak rise above the 0 min value were significantly lower (195.4 \pm 49.9 vs $527.5 \pm 84.9 \mathrm{pmol} / \mathrm{l}, p=0.021$ and $152.7 \pm 49.1 \mathrm{pmol} / \mathrm{l}$ vs $471.5 \pm 86.9 \mathrm{pmol} / \mathrm{l}, \mathrm{p}=0.041$, respectively) during pramlintide than during placebo infusion. There were no significant differences

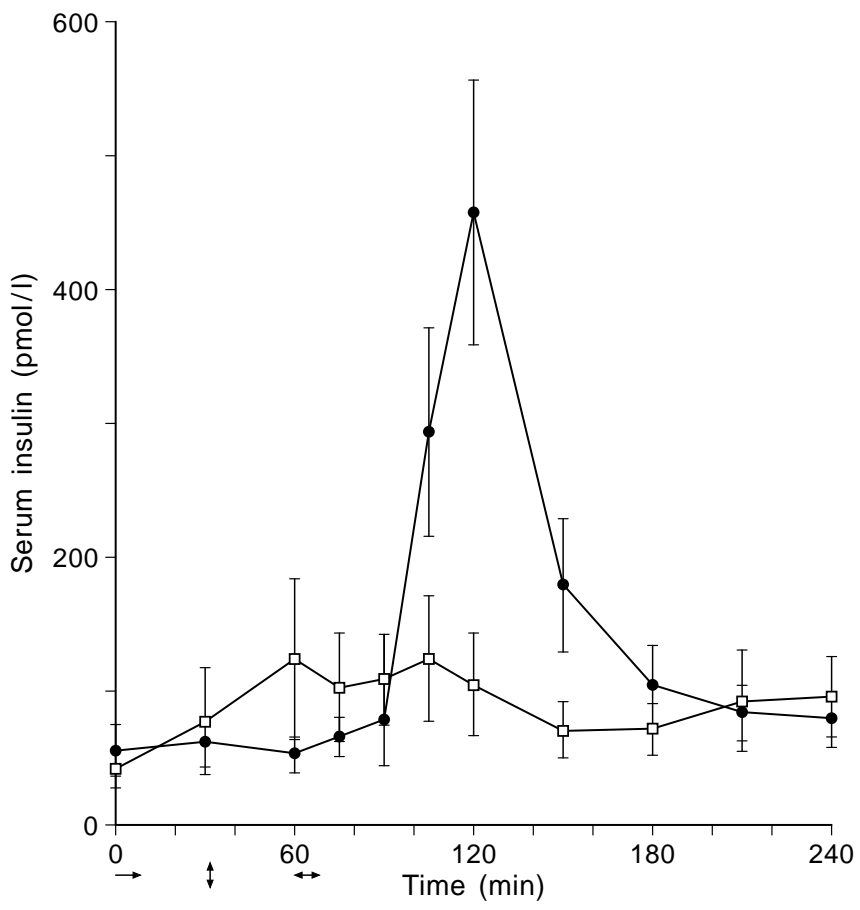

Fig. 2. Serum insulin levels during pramlintide $(\square)$ and placebo ( $)$ infusions. $\rightarrow$ start of 5 -h i.v. infusion, $\hat{\imath}$ time of insulin injection and $\leftrightarrow$ time of meal. Data are mean \pm SEM. The peak serum insulin level and the peak rise above the $O$ value were significantly lower during pramlintide than during placebo infusion

between pramlintide and placebo for other serum insulin values measured.

3-O M G levels. Baseline comparison of plasma 3$O M G$ at 60 min revealed no significant difference between study drugs. When compared to placebo infusion, plasma 3-OMG A U C corrected for the zerohour value during pramlintide infusion wassignificantly lower following the test meal $(8.4 \pm 2.9$ vs $31.7 \pm$ $\left.\left.2.6 \mathrm{mmol} \cdot \mathrm{min}^{-1} \cdot\right|^{-1}, \quad p=0.002\right)$. Peak plasma 3O M G corrected for the zero-hour value was significantly lower during pramlintide than placebo infusion $(0.11 \pm 0.03$ vs $0.21 \pm 0.02, p=0.015)$. There was a trend for prolongation in the time to peak plasma 3OMG level during pramlintide compared to placebo infusion but this did not achieve statistical significance.

SMA blood flow. SMA blood flow at 0 min was the same on the two study days. There was no significant difference in SM A blood flow before or after the test meal between the placebo or pramlintide infusions, but SM A blood flow did increase after the meals.

E ffect on gastric emptying. The figures for the proximal and distal distribution of the meal are shown for illustrative purposes. Statistical analysis was only performed on the "total stomach" emptying data; the results for the proximal and distal stomach are shown in the figures and described qualitatively. 

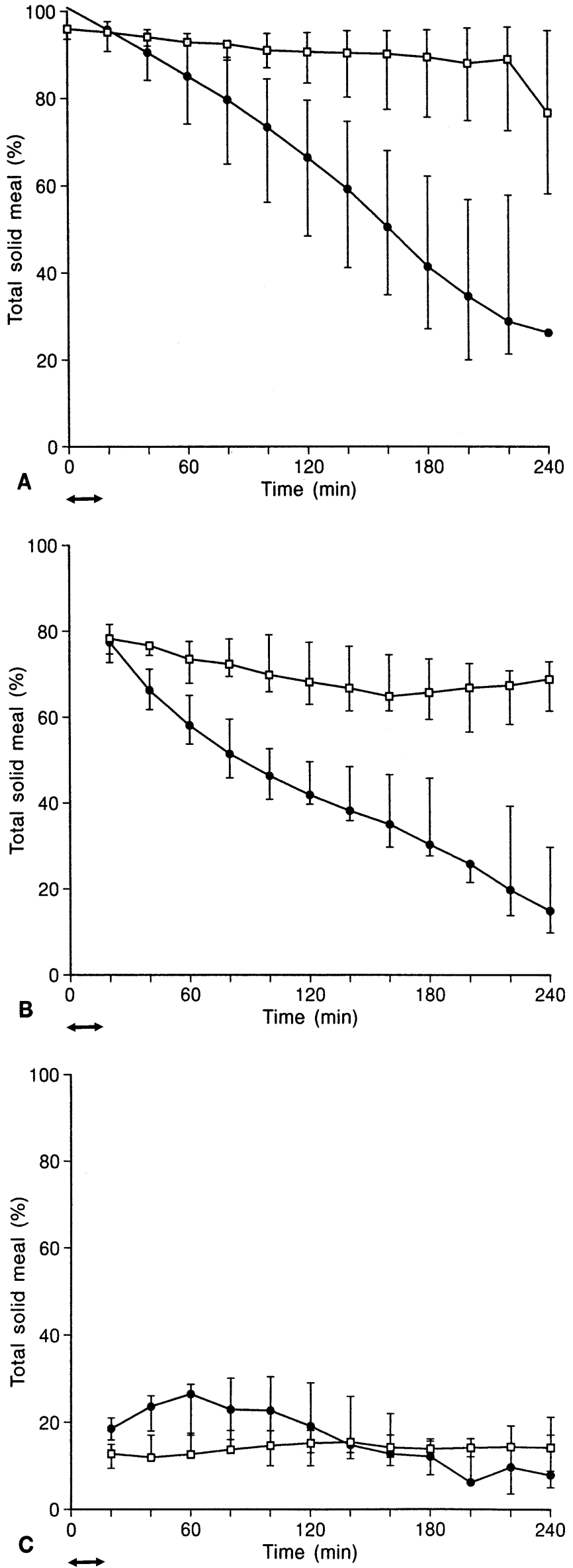

Solid emptying (Fig. 3). Solid emptying from the total stomach (Fig. 3A) was slower during pramlintide infusion compared to placebo. The emptying approximated to a linear pattern. There was a significant difference in lag time between pramlintide and placebo ( 150 vs $44.5 \mathrm{~min}, \mathrm{p}=0.016$ ). The median $t_{50}$ value during placebo infusion was $163.5 \mathrm{~min}$. Pramlintide delayed gastric emptying so much that $t_{50}$ values could not be calculated. The slower emptying during pramlintide infusion could largely be explained by retention in the proximal stomach (Fig. 3B). There was no difference between pramlintide and placebo infusions for retention in the distal stomach (Fig. 3C).

L iquid emptying (Fig.4). Similarly, liquid emptying from the total stomach (Fig. 4A) was slower during pramlintide infusion compared to placebo. There was a significant difference in lag time between pramlintide and placebo (69 vs $7.5 \mathrm{~min}, p=0.008$ ). The median $t_{50}$ value during placebo infusion was 45.0 min. Pramlintide delayed gastric emptying so much that $t_{50}$ values could not be calculated. The slower emptying of the liquid component of the meal was associated with a significant increase in the amount of liquid in the proximal stomach (Fig. 4B). In comparison there was no significant difference in the emptying rate of placebo or pramlintide from the distal stomach (Fig.4C).

Pramlintide infusion therefore resulted in a delay of both the initial phase and the first $50 \%$ of gastric emptying for both the liquid and solid components of the test meal.

The study protocol was well-tolerated by all subjects but, at the end of the infusion of pramlintide, nausea was reported by half the patients two of whom vomited. Nausea was mild and vomiting moderate for three of four ( $75 \%)$ and two of two patients $(100 \%)$, respectively.

\section{Discussion}

The rate of gastric emptying can be affected by a large number of factors including meal composition, blood glucose concentration, insulinaemia and levels of other hormones. We attempted to control these influences. To avoid potential influence of meal

Fig. $\mathbf{3}$ (A - C). Solid gastric emptying during pramlintide ( $\square$ ) and placebo (-) infusions. $\leftrightarrow$ time of meal. $\mathbf{A}$, total; B, proximal; C, distal. D ata are median and interquartile ranges. There was a significant difference in lag time (the time taken for $10 \%$ of the isotope to empty) between pramlintide and placebo ( 150 vs $44.5 \mathrm{~min}, p=0.016$ ). The median $t_{50}$ value (the time at which $50 \%$ of the isotope has left the stomach) during placebo infusion was $163.5 \mathrm{~min}$. Pramlintide delayed gastric emptying so much that $t_{50}$ could not be calculated 

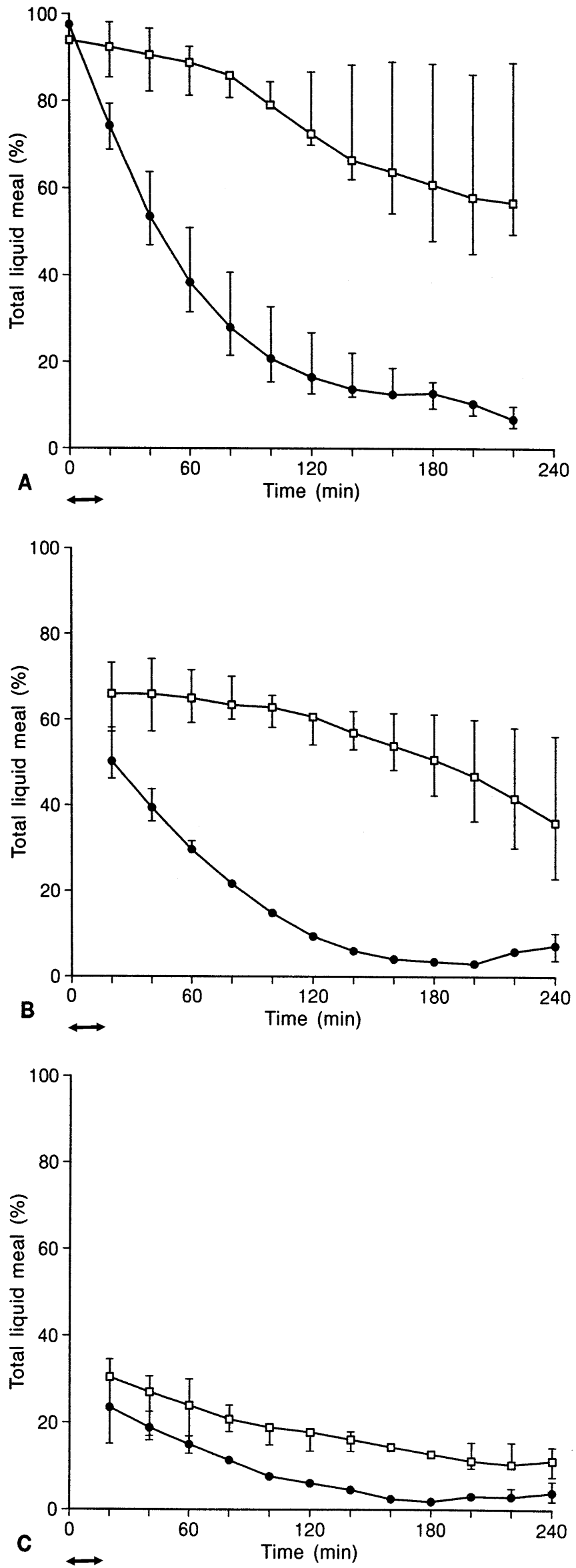

content, the study was designed as a crossover trial and a standardized test meal used. Since hyperglycaemia may delay gastric emptying [11-13], euglycaemia was aimed for. The delayed gastric emptying during pramlintide infusion was not related to postprandial glucose levels which were comparable between pramlintide and placebo except for the peak value, which was lower during pramlintide than placebo infusion. Thus, pramlintide resulted in a delay of gastric emptying despite a higher maximum blood glucose concentration during placebo infusion.

M ore glucose was infused between 90 and $180 \mathrm{~min}$ during pramlintide infusion compared to placebo infusion (data not shown) to maintain blood glucose within the normal postprandial range; this can be explained by pramlintide delaying glucose absorption as a result of the delay in gastric emptying.

$\mathrm{H}$ yperinsulinaemia (approximately $270 \mathrm{pmol} / \mathrm{l}$ ) has been reported to delay gastric emptying in normal subjects [14]. In the present study, insulin concentrations were lower after pramlintide infusion. Therefore the delay in gastric emptying during pramlintide infusion was not an effect of insulin.

There was a big difference in insulin levels between placebo and pramlintide infusions; this was as a result of exogenous insulin given during placebo infusion to prevent postprandial hyperglycaemia (data not shown).

Following gastric emptying glucose is transported across the intestinal wall and enters the circulation. Its absorption rate can be estimated using double isotope labelling techniques. H owever, since $3-0$ M G is actively transported across the small intestine [15], but is not metabolized after absorption [16], this glucose analogue can serve as an indicator of active monosaccharide absorption. D elayed absorption of 3-O M G would be consistent with an effect secondary to delayed gastric emptying. (H owever, a large effect of pramlintide on gastric emptying would prevent detection of any additional direct effect of pramlintide on absorption of glucose.) In addition, if there was a change in the SM A - which supplies the second part of the duodenum, jejunum, ileum but not the stomach which is supplied by the coeliac artery-blood flow response to food during pramlintide infusion, this would indicate that vascular effects of pramlintide may contribute to any attenuation of the postprandial glucose excursion.

Fig.4 (A - C). Liquid gastric emptying during pramlintide ( $\square$ ) and placebo ( $\bullet$ ) infusions. $\leftrightarrow$ time of meal. D ata are median and interquartile ranges. There was a significant difference in lag time (the time taken for $10 \%$ of the isotope to empty) between pramlintide and placebo ( 69 vs $7.5 \mathrm{~min}, p=0.008$ ). The median $t_{50}$ value (the time at which $50 \%$ of the isotope has left the stomach) during placebo infusion was $45.0 \mathrm{~min}$. Pramlintide delayed gastric emptying so much that the $t_{50}$ value could not be calculated 
The absorption of 3-OMG was delayed during pramlintide infusion. This was probably secondary to the delay of gastric emptying as there was an inverse relationship between liquid emptying and the 3OM G profile: as liquid emptied from the stomach, 3OM G levels started to rise. O ther mechanisms, such as an effect of pramlintide on intestinal transport are possible but were not evaluated.

There was no difference in SMA blood flow between placebo and pramlintide infusion visits, either before or after the test meal. This is slightly surprising since it has been reported that increased gut blood flow is associated with the absorption of nutrients [17] and a difference in SMA blood flow between the placebo and pramlintide infusions would be expected given the relationship between the rate of gastric emptying of food from the stomach and the blood flow response. The lack of difference in SM A blood flow responses suggests that there are other factors, of which we are unaware, which may also play a role in the local regulation of intestinal blood flow.

For both phases of the meal the delay of emptying by pramlintide appears to be due to the retention of both the solid and liquid in the proximal stomach region. During placebo infusion the solid component of the meal initially resided in the proximal stomach. However, the liquid component rapidly emptied from the stomach with no evidence of preferential storage in the proximal stomach. Similar findings have been reported by other workers [18]. In the latter study proximal and distal stomach emptying of a solid (100 g of ${ }^{99 \mathrm{~m} T \mathrm{~T}}$ labelled liver/ground beef) and liquid (either $200 \mathrm{ml}$ of $0.9 \% \mathrm{NaCl}$ or $25 \%$ dextrose solutions) mixed meal was quantified in normal subjects and it was found that the dextrose drink delayed gastric emptying of the solid meal compared with saline by increasing the lag period and retention in the proximal stomach. This could possibly be due to a delay of emptying caused by endogenous amylin and/or insulin which will have been co-secreted in response to the glucose drink. In the present study, pramlintide caused retention of food and drink in the proximal stomach, and thus may be an extension of the effects of glucose described by Collins et al. [18].

Nausea and vomiting can have major effects on gastric motility and retard gastric emptying. However, they occurred at the end of the infusion period and after the gastric emptying images were completed. It is likely they were a consequence of delayed emptying/gastric stasis rather than a cause.

R ecently, Kolterman et al. [5] have shown that pharmacological doses of pramlintide (mean plasma concentration $225 \pm 15 \mathrm{pmol} / \mathrm{l}$ ) reduced postprandial hyperglycaemia in patients with ID D M after oral nutrients, but had no effect on plasma glucose concentrations after an intravenous glucose load. It was postulated that an alteration in the rate of gastric emptying accounted for at least a portion of the observed reduction in postprandial hyperglycaemia. O ur data support this hypothesis.

The extent of the delay of gastric emptying demonstrated in thistrial probably represents an exaggerated pharmacological effect, since pramlintide was administered as an infusion and the plasma concentrations achieved were several times higher than those anticipated to be required for a therapeutic effect (normal plasma amylin concentrations range between 5 and 20-25 pmol/l in humans whereas peak plasma pramlintide concentration was $130.3 \pm 18.9 \mathrm{pmol} / \mathrm{l})$. Further studies, using a lower pramlintide infusion rate to achieve a concentration corresponding to a physiological amylin concentration, are needed. Pramlintide can be administered by intermittent subcutaneous injections [19] which would obviously be a more appropriate therapeutic route than intravenous infusion. In this study the patient's usual insulin regimen was not changed as part of the protocol but it might be anticipated that less short-acting insulin would be required to control postprandial glucose excursion since prolonging the period of nutrient absorption has been shown to enhance insulin "economy" [20].

IDDM patients are not only insulin deficient but also amylin deficient [21, 22]. Faster rates of gastric emptying have been reported not only in rat models of IDDM [4,23] but also in humans with IDDM $[24,25]$ and it has been suggested that amylin deficiency may contribute to postprandial hyperglycaemia. There is also indirect evidence of enhanced gastric emptying in IDD M ; Pehling et al. [26] reported that meal-derived glucose appeared in the systemic circulation more rapidly in well-controlled IDDM patients compared to age-matched non-diabetic control subjects. If recent reports of faster rates of gastric emptying in patients with IDDM are confirmed, slowing the rate of gastric emptying in these patients might prove beneficial in improving glycaemic control and therefore amylin or an amylin agonist may be a useful adjunct to insulin treatment by regulating absorption of ingested nutrients by modifying gastric emptying. H owever, since there is evidence for both accelerated and delayed gastric emptying in IDDM $[24,25,27,28]$, the drug should be reserved for patients identified to have rapid emptying.

A cknowledgements. We wish to thank D r. M . F. L aker, from the D epartment of Clinical B iochemistry, R oyal Victoria H ospital, Newcastle for performing the plasma 3-O MG assays and Dr. $M$. Frier, R adiopharmacy unit, $U$ niversity of N ottingham $M$ edical School, for dispensing and drug accountability.

\section{References}

1. R ink TJ, Beaumont K, Koda J, Y oung A (1993) Structure and biology of amylin. Trends Pharmacol Sci 14: 113-118

2. Thompson R G, G ottlieb A B , Peterson J (1995) The human amylin analogue A C 137 reduces mean 24 hour glucose in type 1 diabetes. D iabetologia 38 [Suppl 1]: A 44 (A bstract) 
3. Brown K, Menius A, Sandefer E, Edwards J, James M (1994) The effects of amylin on changes in plasma glucose and gastric emptying following an oral glucose load in conscious dogs. D iabetes 43 [Suppl 1]: $172 \mathrm{~A}$ (A bstract)

4. Young A A, G edulin B, Vine W, Percy A, Rink TJ (1995) $G$ astric emptying is accelerated in diabetic $B B$ rats and is slowed by subcutaneous injections of amylin. Diabetologia 38: $642-648$

5. Kolterman OG, G ottlieb A, M oyses C, Colburn W (1995) R eduction of postprandial hyperglycaemia in subjects with ID D M by intravenous infusion of A C 137, a human amylin analogue. Diabetes Care 18: 1179-1182

6. Frier M, Perkins A C (1994) R adiopharmaceuticals and the gastrointestinal tract - review article. Eur J Nucl Med 21: 1234- 1242

7. Hardy J G, Perkins A C (1985) Validity of the geometric mean correction in the quantification of whole bowel transit. N ucl Med Commun 6: 217-224

8. Q amar M I, R ead A E , Skidmore R, E vans J M, Wells PNT (1986) Transcutaneous Doppler ultrasound measurement of superior mesenteric artery blood flow in man. Gut 27 : 100-105

9. Laker M F, Mount J N (1980) M annitol estimation in biological fluids by gas-liquid chromatography of trimethylsilyl derivatives. Clin Chem 26: 441-443

10. Laker MF (1979) Estimation of disaccharides in plasma and urine by gas-liquid chromatography. J Chromatogr 163: $9-18$

11. M acG regor I, G ueller R, Watts H, M eyer J (1976) The effects of acute hyperglycaemia on gastric emptying in man. Gastroenterology 70: 190-196

12. Fraser $R, H$ orowitz $M, M$ addox $A, H$ arding $P, C$ hatterton B, D ent J (1990) Hyperglycaemia slows gastric emptying in type 1 (insulin-dependent) diabetes mellitus. D iabetologia $33: 675-680$

13. H orowitz $M, H$ arding $P, M$ addox A F et al. (1989) G astric and oesophageal emptying in patients with type 2 (non-insulin-dependent) diabetes mellitus. Diabetologia 32: 151159

14. E liasson B, Björnsson $E$, U rbanavicius $V$ et al. (1995) H yperinsulinaemia impairs gastrointestinal motility and slows carbohydrate absorption. D iabetologia 38: 79-85

15. L aker M F, Bull HJ, M enzies IS (1982) E valuation of mannitol for use as a probe marker of gastrointestinal permeability in man. E ur J Clin Invest 12: 485-491
16. Fordtran J S, Clodi PH, Soergel KH, Ingelfinger FJ (1962) Sugar absorption tests, with special reference to 3-0-methyl-D-glucose and D-xylose. A nn Intern M ed 57: 883-891

17. Q amar M I, R ead A E, M ountford R (1986) Increased superior mesenteric blood flow after glucose but not after lactose ingestion. Q J M ed 60: 893-896

18. Collins PJ, Houghton LA, Read NW et al. (1991) R ole of the proximal and distal stomach in mixed solid and liquid meal emptying. G ut 32: 615-619

19. Kolterman O G, Schwartz S, Corder C et al. (1996) E ffect of 14 days' subcutaneous administration of the human amylin analogue, pramlintide (A C 137), on an intravenous insulin challenge and response to a standard liquid meal in patients with ID D M . D iabetologia 39: 492-499

20. Jenkins D JA, Wolever TM S, O cana A M (1990) M etabolic effects of reducing rate of glucose ingestion by single bolus versus continuous sipping. D iabetes 39: 775-781

21. Bennet W M, Smith D M, B loom SR (1994) Islet amyloid polypeptide: does it play a pathophysiological role in the development of diabetes? D iabet M ed 11: 825-829

22. Koda J E, Fineman M, Rink TJ, D ailey GE, M uchmore D B, Linarelli LG (1992) A mylin concentrations and glucose control. L ancet 339: 1179-1180

23. N owak TV, R oza A M, Weisbruch J P, B rosnan M R (1994) A ccelerated gastric emptying in diabetic rodents: effect of insulin treatment and pancreas transplantation. J L ab Clin M ed 123(1): 110-116

24. N owak TV, J ohnson CP, Kalbfleisch J H et al. (1995) H ighly variable gastric emptying in patients with insulin dependent diabetes mellitus. G ut 37: 23-29

25. K eshavarzian A , I ber FL, Vaeth J (1987) G astric emptying in patients with insulin requiring diabetes mellitus. A $\mathrm{m}$ J G astroenterol; 82: 29-35

26. Pehling G, Tessari P, G erich J E , H aymond M W, Service FJ, R izza R A (1984) A bnormal meal carbohydrate disposition in insulin-dependent diabetes. J Clin Invest 74: 985-991

27. H orowitz M , M addox A F, Wishart J M , H arding PE, Chatterton BE, Shearman DJC (1991) R elationships between oesophageal transit and solid and liquid gastric emptying in diabetes mellitus. E ur J Nucl M ed 18: 229-234

28. M ecklenbeck W, Rathmann W, Vosberg H (1991) Gastric emptying in diabetic neuropathy: two different forms of disturbed kinetics. Eur J Nucl Med 18: FP-3H 3-1 (A bstract) 